\title{
La influencia del hábito lector en el empleo de internet: un estudio con jóvenes universitarios
}

\author{
María Elche Larrañaga* \\ Santiago Yubero*
}

Artículo recibido:

2 de julio de 2018

Artículo aceptado:

16 de noviembre de 2018

Artículo de investigación

\section{Resumen}

La universidad exige prácticas de búsqueda, obtención, evaluación, procesamiento e interpretación de la información en soporte digital, por lo que los estudiantes han de llegar a ser expertos decodificadores y lectores críticos, pero no basta con ser nativos digitales. Para aprovechar las potencialidades de la web 2.0 es imprescindible que se posea competencia lectora. A partir de los resultados de esta investigación, realizada con una muestra significativa de estudiantes provenientes de distintas universidades, se definen perfiles específicos del uso de internet vinculados con el

* Facultad de Ciencias de la Educación y Humanidades, Universidad de Castilla-La Mancha, Cuenca, España

maria.elche@uclm.es santiago.yubero@uclm.es

INVESTIGACIÓN BIBLIOTECOLÓGICA, vol.33, núm. 79, abril/junio, 2019, México, ISSN: 2448-8321 pp. 51-66 
hábito lector. Los datos revelan que los universitarios no explotan al máximo las posibilidades de desarrollo académico y de aprendizaje que les brinda internet. Se reafirma la necesidad de insertar la lectura en el proyecto académico-profesional, asumiendo las TIC como un instrumento esencial para el aprendizaje.

Palabras clave: Comprensión lectora; Competencia digital; Hábito lector; Estudiantes universitarios

The influence of reading habits on the use of internet: a study with university students

María Elche Larrañaga and Santiago Yubero

\section{Abstract}

The university requires practices of searching, obtaining, evaluating, processing and interpreting information in digital format, so that students have to become expert decoders and critical readers, but it is not enough to be digital natives. In order to take advantage of the potentialities of web 2.0, it is essential to have reading competence. Based on the results of this research, carried out with a significant sample of students from different universities, specific profiles of the use of the internet linked to the reading habit are defined. The data reveal that university students do not exploit to the maximum the possibilities of academic development and learning that the internet offers them. The need to insert reading into the academic-professional project is reaffirmed, assuming ICT as an essential instrument for learning.

Keywords: Reading Comprehension; Digital Competence; Reader Habit; University Studentes

\section{INTRODUCCIÓN}

L as generaciones jóvenes son representantes de las nuevas formas de comportamiento social y cultural basadas en el uso habitual de las distintas tecnologías digitales (Area-Moreira, 2012). A estas personas, que han nacido 
en la era digital y manejan estas tecnologías de forma normalizada en casi todos los aspectos de su vida, se les describió inicialmente como nativos digitales (Prensky, 2001) y más recientemente como residentes digitales (White y Le-Cornu, 2011) o Google generation (Rowlands et al., 2008). Son los mismos que conforman el alumnado universitario actual, la mayoría nacidos en un mundo transformado por las tecnologías y para quienes internet constituye un entorno normal de desarrollo.

Las TIC tienen un gran potencial para acercar a los estudiantes universitarios a los conocimientos que deben adquirir. En este contexto, el Espacio Europeo de Educación Superior ha llevado a las aulas una renovación metodológica, dando cabida a las nuevas formas de comunicar, producir información y generar conocimiento.

En la cultura multimodal del siglo XXI los universitarios han de poseer las competencias necesarias para seleccionar la información, organizarla y transformarla en conocimiento, independientemente del soporte en el que se reciba (Area-Moreira y Guarro, 2012). Consideramos que para que esto ocurra es necesario seguir desarrollando la habilidad tradicional de la lectura ya que, tal como señala Millán (2000: 21), "la lucha por comprender y utilizar las nuevas tecnologías digitales exige muchas cosas nuevas, pero presupone las antiguas. Y la más importante de ellas es la lectura”.

\section{Jóvenes e internet}

Para los jóvenes la Red se ha convertido en una plataforma imprescindible para muchas tareas de carácter cotidiano, actividades que tienen que ver con el ocio y la diversión y algunas más especializadas y de uso profesional.

Los datos del informe elaborado por López-Ruiz (2017) para la Fundación SM y el Observatorio de la Juventud en Latinoamérica revelan que 76.4 \% emplea internet para "cosas relacionadas con los estudios". Los resultados de los informes del Instituto de la Juventud (2013) evidencian que los estudiantes universitarios son uno de los colectivos más activos en el consumo de internet en relación con su formación. De los jóvenes universitarios, $84.6 \%$ accede varias veces al día a internet, realizando búsquedas de información $(73.9 \%$ ) y descargando contenidos $(62.6 \%)$. Cuando las tareas se vuelven más complejas y requieren mayor implicación, el empleo de internet es más bajo (Gutiérrez-Porlán, Román-García y Sánchez-Vera, 2018). Es más frecuente el uso de los sistemas de mensajería instantánea (Gutiérrez-Porlán, Román-García y Sánchez-Vera, 2018; Ministerio del Interior, 2014).

Creemos necesario realizar investigaciones que exploren el uso real que los jóvenes universitarios están haciendo de la web 2.0 para producir modelos 
para la intervención desde el contexto universitario. Por otro lado, Bennett y Maton (2010) afirman que es relevante conocer, además del uso que hacen los jóvenes de la tecnología, el valor que le conceden.

\section{Universidad e internet}

Los métodos docentes tradicionales están en desuso. Ahora, además de los textos aportados por el profesor, hay numerosas fuentes de interés académico en internet. Sin embargo, hay autores que plantean que estos cambios no suponen un avance significativo hacia la enseñanza virtual sino que, simplemente, se ha trasladado la metodología tradicional de las aulas a las plataformas virtuales. En esta misma línea hay quienes identifican las plataformas virtuales como sustitutorias de la reprografía (artículos, textos, instrucciones, trabajos) (Pérez-Lorido, 2008; García-Rueda, 2008). En muchos casos, internet sería más una plataforma de almacenamiento que un medio de aprendizaje. El avance ha de suponer que el alumno no se limite a estudiar exclusivamente los apuntes ofrecidos por el profesor, sino que sea un buscador crítico de información y generador de su propio conocimiento. Los estudiantes universitarios han de llegar a ser expertos decodificadores y lectores críticos. No basta con ser nativos digitales para tener una alta competencia en el empleo de internet, como afirman Boyd (2014) o Cabra-Torres y Marciales-Vivas (2009). Lo que aquí planteamos, como señalan, entre otros, Amiama-Espaillat y Mayor-Ruiz (2017), es que para aprovechar las potencialidades de la web 2.0 es imprescindible que se posea competencia lectora.

\section{Lectura e internet}

Hoy leemos en pantallas, en entornos digitales diversos (Cassany, 2016). La Federación de Gremios de Editores de España (2018), en su informe de 2017, reveló que $76.3 \%$ de los españoles mayores de 14 años habían leído algún tipo de contenido en soporte digital.

La proliferación de dispositivos electrónicos de lectura, en convergencia con la expansión de internet, están transformando la figura del lector (Bustamante, 2017; Cordón-García, 2016). El comportamiento lector hoy es más diverso, por eso, McKenna et al. (2012) proponen medir la práctica lectora incluyendo tanto el formato digital como el formato impreso. Y es que, como afirma Cassany (2016), la lectura digital mantiene la esencia de la lectura tradicional; por ello, no pueden separarse los usos de la lectura digital de los hábitos lectores. En la misma línea, Subrahmanyam, Smahel y Greenfield (2006) señalan que suele existir una coherencia entre el comportamiento en 
la vida on- y offline, por lo que podemos pensar que el comportamiento lector del sujeto puede ser un elemento mediador en los usos de la red.

Atendiendo a la ausencia de trabajos sobre la relación del uso de las nuevas tecnologías y el comportamiento lector en estudiantes universitarios, y con el fin de aportar resultados empíricos que nos sitúen ante una aproximación real de la situación actual, el objetivo de esta investigación ha sido explorar las actividades que realizan estos jóvenes en internet y la importancia que le conceden y examinar las diferencias en función de su hábito lector. A partir de estos objetivos, nos planteamos las siguientes hipótesis de estudio:

- Hipótesis 1: el empleo de internet está relacionado con las prácticas de lector voluntario.

- Hipótesis 2: el hábito de lectura define perfiles diferenciados en el empleo de la red.

\section{Método}

\section{Participantes}

Para el presente estudio se contó con una muestra total de 1833 estudiantes universitarios, provenientes de cuatro universidades: 881 (48.1\%) de la Universidad de Castilla-La Mancha; 733 (40\%) de la Universidad de Santiago de Compostela; 123 (6.7 \%) de la Universidad de Valencia y 96 (5.2 \%) de la Universidad Pablo de Olavide de Sevilla. Se trata de estudiantes de los grados de educación social, trabajo social, educación infantil, educación primaria y pedagogía. El sexo está sesgado debido al origen de la muestra, 84.3\% son mujeres. El rango de edad es de 18 a 52 años, con una media de 21.44 y una desviación típica de 3.55.

\section{Instrumento}

Las preguntas del cuestionario fueron agrupadas en tres apartados: 1) datos generales: edad, sexo, grado, universidad; 2) internet: nivel de importancia que conceden a internet según las diferentes finalidades y actividades que realizan en la web; 3) lectura: hábito de lectura y frecuencia de lectura en soporte digital.

En relación con el segundo apartado, los alumnos debían indicar qué importancia tenía para ellos internet, en una escala de 1 a 10, en cuatro categorías empleadas previamente en el estudio de Dornaleteche, Buitrago y 
Moreno (2015): para comunicarse, para estar informado de la actualidad, como entretenimiento y para estudiar.

Para las actividades en la web, se ha aplicado una adaptación del Test de Alfabetización Digital On-line de Dornaleteche, Buitrago y Moreno (2015), que consta de 15 ítems. Los alumnos debían indicar la frecuencia con la que usaban cada uno de los instrumentos propuestos en una escala de cinco puntos: 1. Nunca, 2. Alguna vez al mes, 3. Alguna vez a la semana, 4. Alguna vez al día, 5. Varias veces al día. Nosotros, por interés del estudio, añadimos la categoría Leer/descargar libros (Tabla 3). Los autores proponen el empleo de la puntuación total, que alcanzó una fiabilidad de 0.74 .

Para el hábito de lectura fueron empleadas dos preguntas del cuestionario de hábitos lectores elaborado por el Centro de Estudios de Promoción de la Lectura y la Literatura Infantil y Juvenil (CEPLI) para estudiantes universitarios (Larrañaga y Yubero, 2005): frecuencia de lectura voluntaria y número de libros leídos en el último año.

Con respecto a la lectura digital, se empleó la pregunta de frecuencia de lectura en soporte digital del Barómetro de Hábitos de Lectura y Compra de Libros en España de la Federación de Gremios de Editores de España.

\section{Procedimiento}

El muestreo se realizó por conglomerados, tomando el aula como unidad muestral. Los cuestionarios fueron pasados en el aula de clase, previa autorización de los profesores colaboradores y en los espacios que ellos indicaron. Se explicó la finalidad y las condiciones de estudio. La participación fue voluntaria y anónima y se aseguró la confidencialidad.

\section{Análisis de datos}

En primer lugar, para evaluar el hábito lector se seleccionaron dos preguntas de lectura voluntaria: la frecuencia de lectura y el número de libros leídos por placer durante el último año. Esta medida ya había sido utilizada en investigaciones previas sobre el análisis del comportamiento lector en estudiantes universitarios (Larrañaga y Yubero, 2005; Yubero y Larrañaga, 2015), y se había informado que en los resultados del cruce de respuestas entre ambas variables aparecían resultados inconsistentes. Se encontraban sujetos que informaban de comportamiento lector en una variable y de comportamiento no lector en la otra; parecía que algunos estudiantes querían ofrecer una imagen diferente 
a la real. Cruzamos ambas variables para construir el hábito lector. Sólo consideramos "lector habitual" a los sujetos que responden en esta categoría en las dos variables. Consideramos como "lector ocasional" a los sujetos en los que se produce el cruce de dos valoraciones de lector ocasional y el cruce de lector habitual con lector ocasional. Entra en la categoría de "no lector" el cruce de no lector en ambas categorías. La combinación de "no lector" en cualquiera de las dos variables con una valoración de lector (ocasional o habitual) en la otra se designó como sujeto "falso lector", por entender que realmente no es lector pero quiere dar una imagen lectora. De esta manera, se obtienen cuatro grupos de lectores:

- No lectores: no leen nunca o casi nunca. Entre 0 y 2 libros al año.

- Lectores ocasionales: leen alguna vez al trimestre o al mes. Entre 3 y 10 libros al año.

- Lectores frecuentes: leen casi todos los días o más de una vez a la semana. Más de 10 libros al año.

- Falsos lectores: aquellos que en una variable se muestran como lectores y en la otra como no lectores.

Posteriormente, en función de los grupos de hábito lector, se analizaron las diferencias en la frecuencia de la lectura en soporte digital a través de chi-cuadrado y de la importancia de internet y las actividades realizadas a través de la comparación de medias y contrastes de Anovas. En último lugar, se realizaron regresiones lineales sobre cada una de las actividades en la red analizadas, incluyendo las variables de estudio: lectura en soporte digital, hábito lector e importancia de internet.

\section{Resultados}

De los estudiantes universitarios, $39.1 \%$ lee todos los días en soporte digital (LF), la mitad lee en soporte digital alguna vez al mes o a la semana y $9.6 \%$ no lee nunca en soporte digital (Tabla 1). Respecto al comportamiento de lectura voluntaria, $20.3 \%$ de los estudiantes universitarios son no lectores. En la categoría de falsos lectores entra $26.9 \%$, lo que supone un total de $47.2 \%$ de alumnos no lectores. De los universitarios lectores, $42.9 \%$ son lectores ocasionales y $9.9 \%$ son lectores habituales.

En la Tabla 1 se encuentran los porcentajes de la frecuencia de lectura en soporte digital segmentados según el hábito lector, que se distribuyen significativamente de manera diferencial. Los estudiantes lectores, tanto los 
lectores ocasionales como los lectores habituales, leen mayoritariamente con frecuencia diaria en soporte digital. Los no lectores y los falsos lectores se distribuyen entre la lectura mensual, semanal y diaria.

\begin{tabular}{|l|c|c|c|c|c|c|}
\hline & Total & NL & FL & L0 & LH & \multirow{2}{*}{$\chi^{2}$} \\
\cline { 1 - 6 } Nunca & 9.6 & 15.8 & 6.8 & 9.3 & 6.1 & \multirow{2}{*}{$391.02^{\text {*** }}$} \\
\cline { 1 - 5 } Alguna vez al mes & 23.6 & 28.6 & 26.5 & 21.5 & 15.6 & \\
\cline { 1 - 5 } Alguna vez a la semana & 27.6 & 26.1 & 26.9 & 28.9 & 26.3 & \\
\cline { 1 - 5 } Todos los días & 39.1 & 29.4 & 39.7 & 40.3 & 52.0 & \\
\hline
\end{tabular}

Tabla 1. Frecuencia de lectura en soporte digital según el hábito lector (porcentajes) Nota: NL: No lector; FL: Falso lector; LO: Lector ocasional; LH: Lector habitual ${ }^{\star} p<0.05 ;{ }^{* \star} p<0.01 ;{ }^{* \star *} p<0.001$

Para los alumnos universitarios internet es muy importante, con valoraciones medias por encima de ocho en una escala de 10 puntos. Todos los universitarios priorizan su importancia como instrumento de comunicación y también para estar informados de la actualidad. Los estudiantes no lectores y falsos lectores ubican en tercera posición el empleo de internet para entretenerse y en último lugar para estudiar. Los lectores ocasionales y habituales destacan la importancia de la lectura para el estudio por encima del entretenimiento. Los universitarios no lectores le dan más importancia a internet para comunicarse ( $p$ falsos lectores $<0.001$, plectores ocasionales $<0.01$, plectores habituales $<0.001$ ) y para el entretenimiento ( $p$ falsos lectores $<0.05$, plectores ocasionales $<0.001$, plectores habituales $<0.001$ ). Los falsos lectores se equiparan con los lectores ocasionales en estas categorías (comunicarse, $p=0.366$, entretenimiento, $p=0.254$ ), mientras que para los lectores habituales tiene menos importancia internet como instrumento de entretenimiento y de comunicación (Tabla 2).

\begin{tabular}{|l|c|c|c|c|c|c|c|}
\hline & Total & NL & FL & L0 & LH & $\boldsymbol{F}$ & $\boldsymbol{\eta}$ \\
\hline Comunicación & 8.96 & 9.22 & 8.88 & 8.95 & 8.71 & $7.02^{\text {***}}$ & 0.11 \\
\hline Entretenimiento & 8.29 & 8.54 & 8.33 & 8.22 & 7.94 & $6.80^{\text {** }}$ & 0.10 \\
\hline Actualidad & 8.67 & 8.71 & 8.71 & 8.67 & 8.46 & 1.57 & 0.05 \\
\hline Estudiar & 8.29 & 8.30 & 8.28 & 8.32 & 8.21 & 0.22 & 0.02 \\
\hline
\end{tabular}

Tabla 2. Importancia de internet según el hábito lector (medias)

Nota: NL: No lector; FL: Falso lector; LO: Lector ocasional; LH: Lector habitual ${ }^{*} \mathrm{p}<0.05 ;{ }^{* *} \mathrm{p}<0.01 ;{ }^{* * *} \mathrm{p}<0.001$

Las actividades que realizan los estudiantes en la red se presentan en la Tabla 3. Hemos agrupado estas actividades según su utilidad principal. Diferenciamos 
entre actividades sociales, actividades de ocio, actividades de búsqueda de información y actividades creativas. Entendemos que las actividades más vinculadas con el contexto universitario son las dos últimas. Hemos optado por presentarlas en la tabla ordenadas de forma descendente, según su empleo.

Las actividades sociales predominan sobre las demás funciones de internet; le siguen las actividades de búsqueda, a continuación, las de ocio y, por último, las actividades creativas. En los estudiantes no lectores el ocio sobrepasa las actividades de búsqueda.

No se producen diferencias significativas del empleo total de la red entre los grupos de estudio, ni tampoco en las actividades sociales, ni de ocio, ni las actividades creativas. Sí se encuentran diferencias significativas en las actividades de búsqueda, siendo los estudiantes lectores los que más las llevan a cabo y, de manera similar, también los lectores ocasionales y los lectores habituales $(p=0.408)$.

Sin embargo, si analizamos de manera independiente las actividades de cada categoría, observamos diferencias significativas. Dentro de las actividades sociales, los estudiantes no lectores y falsos lectores hacen un uso similar de las redes sociales $(p=0.848)$, superior a los lectores (no lector: $p$ lector ocasional $<0.05$, plector habitual $<0.001$; falso lector: plector ocasional $<0.01$, plector habitual<0.001). En las actividades de búsqueda se agrupan los lectores ocasionales y los lectores habituales $(p=0.241)$ en relación con la búsqueda de información especializada, realizando esta actividad más que los otros estudiantes. También destacan los lectores habituales en la lectura digital y la descarga de libros, sobre todas las demás categorías de lectura ( $p$ no lector $<0.001$, $p$ falso lector $<0.001$, plector ocasional $<0.01$ ). En las actividades de ocio, los no lectores emplean internet menos que los lectores para ver cine y series ( $p$ lector ocasional $<0.01$, plector habitual $<0.01$ ) y en la misma medida que los falsos lectores $(p=.274)$; aunque los falsos lectores se equiparan con los lectores en la ficción online (plector ocasional $=0.70$, plector habitual $=0.97$ ). Los no lectores participan más en videojuegos online que los demás estudiantes ( $p$ falso lector $<0.01$, plector ocasional $<0.01$, plector habitual<0.01). En la compra/venta online, los no lectores se equiparan con los falsos lectores $(p=0.064)$ y con los lectores ocasionales $(p=0.189)$, realizando este comportamiento más que los lectores habituales $(p<0.01)$. Por último, en la categoría de actividades creativas, los no lectores y los falsos lectores ven, editan y comparten imágenes online en la misma medida $(p=0.095)$ y con mayor frecuencia que los lectores habituales (no lectores: $p$ lector ocasional $<0.001$, plector habitual $<0.001$, falsos lectores: plector ocasional $<0.05$, plector habitual $<0.001)$. También se observa que comparten más información los lectores ocasionales que los no lectores $(p<0.001)$. 


\begin{tabular}{|c|c|c|c|c|c|c|c|}
\hline & Total & NL & $\mathrm{FL}$ & LO & LH & $\boldsymbol{F}$ & $\eta$ \\
\hline Actividades sociales & 3.67 & 3.64 & 3.69 & 3.67 & 3.65 & 0.75 & 0.03 \\
\hline Mensajería instantánea & 4.68 & 4.65 & 4.70 & 4.70 & 4.68 & 0.31 & 0.02 \\
\hline Redes sociales & 4.62 & 4.69 & 4.70 & 4.58 & 4.40 & $6.93^{\star \star \star}$ & 0.11 \\
\hline E-mails & 4.00 & 4.04 & 3.99 & 4.02 & 3.93 & 0.82 & 0.04 \\
\hline Foros & 1.71 & 1.67 & 1.65 & 1.75 & 1.78 & 1.54 & 0.05 \\
\hline Actividades de búsqueda & 2.95 & 2.76 & 2.89 & 3.04 & 3.09 & $20.60^{\star \star \star}$ & 0.18 \\
\hline Descarga archivos & 3.70 & 3.72 & 3.68 & 3.74 & 3.55 & 1.72 & 0.05 \\
\hline Medios de comunicación & 3.66 & 3.54 & 3.70 & 3.69 & 3.72 & 2.01 & 0.06 \\
\hline Información especializada & 3.62 & 3.52 & 3.58 & 3.70 & 3.61 & $3.25^{\star}$ & 0.07 \\
\hline Leer/descargar libros & 2.45 & 1.81 & 2.25 & 2.72 & 3.16 & $84.82^{\star \star \star}$ & 0.35 \\
\hline Actividades de ocio & 2.82 & 2.82 & 2.79 & 2.85 & 2.81 & 0.68 & 0.03 \\
\hline Cine/series & 3.39 & 3.25 & 3.34 & 3.46 & 3.51 & $3.64^{\star \star}$ & 0.08 \\
\hline Escuchar/compartir música & 3.43 & 3.35 & 3.47 & 3.44 & 3.44 & 0.54 & 0.03 \\
\hline Compra/venta & 2.06 & 2.16 & 2.03 & 2.08 & 1.88 & $3.39^{*}$ & 0.07 \\
\hline Ver/compartir videos & 1.99 & 1.98 & 1.94 & 2.04 & 2.02 & 0.65 & 0.03 \\
\hline Videojuegos & 1.59 & 1.77 & 1.53 & 1.55 & 1.51 & $4.17^{* \star}$ & 0.08 \\
\hline Actividades creativas & 2.44 & 2.46 & 2.43 & 2.45 & 2.38 & 0.46 & 0.03 \\
\hline Editar imágenes & 3.07 & 3.32 & 3.16 & 2.98 & 2.75 & $8.68^{\star \star \star}$ & 0.12 \\
\hline Crear y compartir información & 2.58 & 2.42 & 2.54 & 2.67 & 2.62 & $3.73^{\star *}$ & 0.08 \\
\hline Gestionar contenidos & 1.67 & 1.65 & 1.60 & 1.69 & 1.76 & 1.37 & 0.05 \\
\hline Total & 3.02 & 2.98 & 2.99 & 3.05 & 3.02 & 2.43 & 0.06 \\
\hline
\end{tabular}

Tabla 3. Empleo de internet según el hábito lector (medias)

Nota: NL: No lector; FL: Falso lector; LO: Lector ocasional; LH: Lector habitual

${ }^{*} p<0.05 ;{ }^{* *} p<0.01 ;{ }^{* \star *} p<0.001$

La regresión lineal sobre el total de las actividades en la red marca significación en todas las variables analizadas. Sin embargo, en el análisis independiente de las actividades se puede observar que el peso de cada una de ellas depende de la finalidad con la que se emplea internet (Tabla 4). El hábito lector, que es objetivo de nuestro estudio, sólo obtiene resultados significativos en las actividades de búsqueda. La importancia de internet para el estudio forma parte de las actividades de búsqueda. 


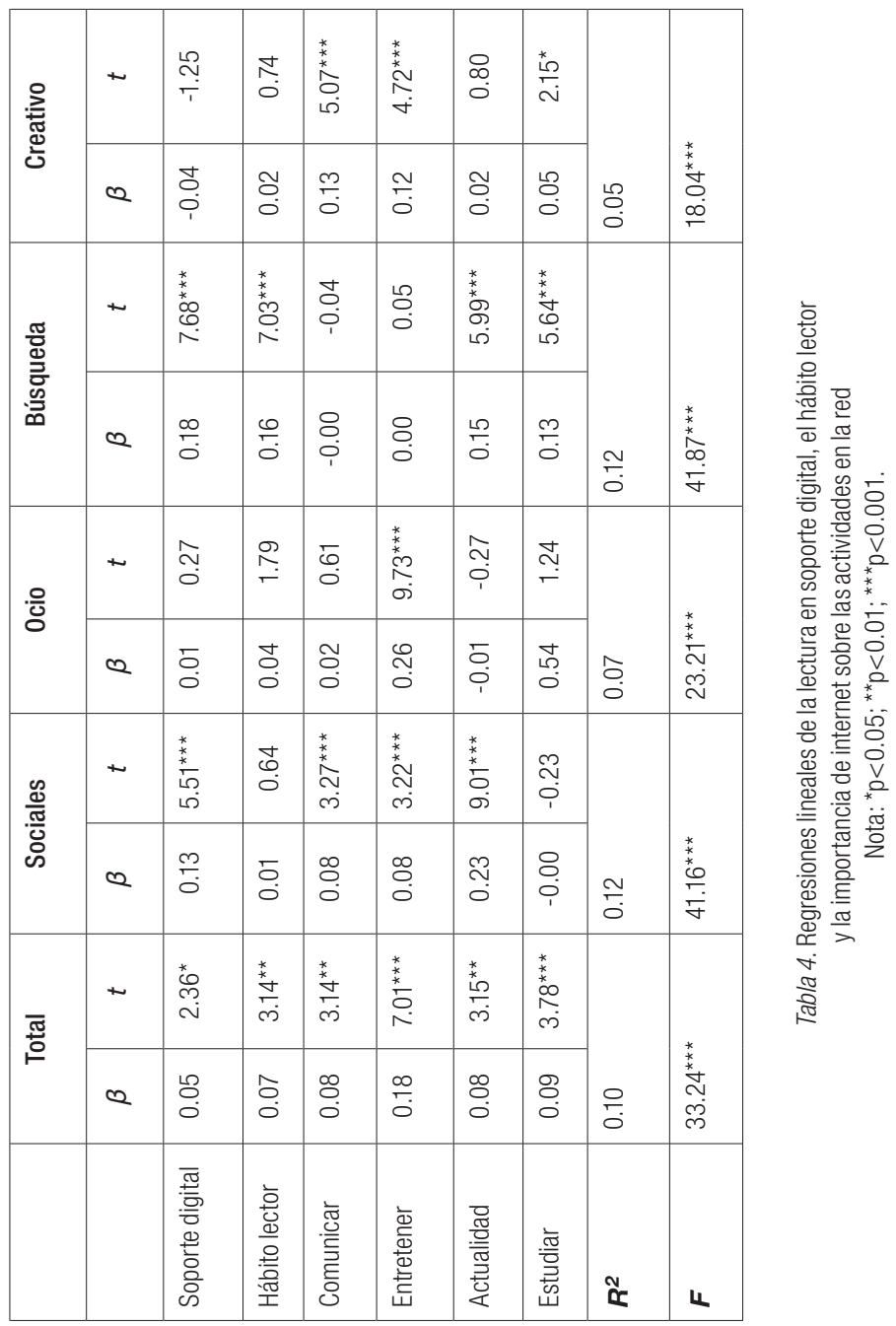




\section{CONCLUSIONES Y DISCUSIÓN}

El objetivo de nuestro trabajo fue explorar el empleo de internet de los estudiantes universitarios y analizar la importancia que le conceden, examinando las diferencias en función del hábito lector.

En relación con el hábito lector, los estudiantes no lectores conceden mayor importancia a internet para la comunicación y el entretenimiento. No se encuentran diferencias entre los grupos en la evaluación de la importancia que se le concede a internet para estar informado de la actualidad, ni para el estudio.

Según los datos obtenidos en este trabajo, más de $90 \%$ de los estudiantes universitarios son lectores en soporte digital; aunque se dan diferencias en la frecuencia de lectura digital en función del hábito lector, siendo los lectores ocasionales y habituales los que la realizan en mayor medida.

Los resultados muestran un predominio claro del empleo social de la web 2.0. Trabajos previos ya habían indicado que internet es básicamente un espacio de interacción (Gutiérrez-Porlán, Román-García y Sánchez-Vera, 2018). En los universitarios, seguramente en parte por ser jóvenes, priman los usos sociales por la necesidad de comunicación y de pertenencia a un grupo social (Colás-Bravo, González-Ramírez y De-Pablos-Pons, 2013). La diferencia que se produce en las actividades sociales, según el hábito lector, se encuentra en el mayor uso de las redes sociales en los estudiantes no lectores y falsos lectores. En cuanto al uso que realizan de internet para ocio, queda reflejado el interés de los lectores por la narrativa (lectores ocasionales y habituales por la visualización de series y películas), mientras que los no lectores lo emplean más para videojuegos online. La red es también una plataforma para el almacenamiento y la difusión de la información. En la universidad parece que se prioriza este uso. Según nuestros resultados, la actividad más frecuente es la descarga de archivos de manera similar en los cuatro grupos de hábito lector. Los lectores ocasionales y habituales buscan más información especializada, a la vez que los lectores habituales leen y descargan más libros. En consonancia con los resultados de investigaciones previas (Dornaleteche, Buitrago y Moreno, 2015; Gutiérrez-Porlán, Román-García y Sánchez-Vera, 2018), nuestros resultados revelan que los universitarios no explotan al máximo las posibilidades de desarrollo académico y de aprendizaje que brinda internet. La categoría de creación de contenidos propios queda relegada al último puesto. Los no lectores y falsos lectores dirigen su creatividad en la red hacia la edición de imágenes, mientras que los lectores ocasionales y habituales, y también los falsos lectores, la orientan hacia la creación de información.

Podemos definir perfiles específicos vinculados con el hábito lector. Los estudiantes no lectores no se definen en un patrón claro de lectura en soporte 
digital. Tienen un perfil pasivo, centrado en la interacción, empleando más las redes sociales y la descarga de archivos. La actividad creativa se dirige hacia la edición de imágenes. También destacan en la importancia que le conceden a internet para el entretenimiento, usándolo más para videojuegos. Siguiendo la terminología de Dornaleteche, Buitrago y Moreno (2015), podríamos decir que los universitarios incluidos en la categoría de no lectores tienen un perfil social y recreativo (socializer). Los estudiantes universitarios lectores realizan la lectura en soporte digital mayoritariamente de forma diaria. Se centran más en la búsqueda de información específica y en el uso de internet para acceder a los medios de comunicación. Su actividad creativa se dirige también a la creación de información. Los resultados indican que estos estudiantes conceden más importancia a internet para su formación. Se trata de un perfil buscador (searcher). Los falsos lectores se encuentran a medio camino; al igual que los no lectores, no muestran un patrón claro de lectura en soporte digital. La importancia que conceden a internet es para comunicarse y como entretenimiento, siendo similar al empleo que hacen los lectores ocasionales. De hecho, acceden con frecuencia a los medios de comunicación y crean y comparten información al mismo nivel que ellos. Sin embargo, en el empleo de redes se asemejan a los estudiantes no lectores, así como en la edición de imágenes.

En las regresiones lineales, el hábito lector entra en las actividades de búsqueda, sin tener peso relevante para las actividades sociales, de ocio y creativas. Este resultado confirma las diferencias en el perfil de empleo de internet en función del hábito lector, siendo los lectores habituales los que presentan un perfil activo de buscador. Además, refuerza los obtenidos en otras investigaciones como las de Millán (2000) y Cassany (2016) sobre la necesidad del desarrollo de la competencia en la lectura tradicional para el mejor aprovechamiento de la lectura digital. Los resultados confirman que es fundamental ser lector para cumplir con mayor eficacia los requisitos de la formación universitaria actual.

La importancia de internet para el estudio se refleja en las regresiones en las actividades de búsqueda y, con un peso muy bajo, en las actividades creativas. Aunque internet se presenta como un espacio privilegiado de interacción social en el contexto universitario, en el uso de la red como medio social no entra la relevancia de internet para estudiar. Estos resultados también pueden estar relacionados con la baja implantación y el escaso uso de las plataformas sociales de internet en el proceso de enseñanza-aprendizaje por parte de las instituciones educativas, informada en otras investigaciones (Duart et al., 2008). Considerados conjuntamente estos resultados, comprobamos su correspondencia con otras investigaciones (Pérez-Lorido, 2008; García-Rueda, 2008) que señalan que en el contexto universitario internet es 
empleado más como un instrumento de almacenamiento que como un medio de interacción social que sirva para el aprendizaje.

Sin duda, un reto principal para construir conocimiento es potenciar la lectura crítica y voluntaria que se asienta en los hábitos lectores, expandiendo el empleo de internet más allá del mero entretenimiento y de la comunicación entre iguales. Desde hace algunos años las universidades han asumido esta nueva función a través de programas centrados en el desarrollo de competencias informáticas e informacionales que, en ocasiones, olvidan que se ha de capacitar a los estudiantes para que sean capaces de utilizar la información de forma eficaz, reflexiva, crítica y responsable. Se requiere, por tanto, insertar la lectura en el proyecto académico-profesional del estudiante, asumiendo que, si bien las TIC son una plataforma esencial para la interacción y el ocio, constituyen también un instrumento esencial para el aprendizaje y la difusión del conocimiento.

Es necesario capacitar a los universitarios para realizar un uso adecuado y completo de las TIC, incluyendo el desarrollo de la competencia lectora que éstas exigen para su formación universitaria y para el desarrollo de su futuro profesional. Además, la sociedad requiere de profesionales que asuman una formación continua para poder afrontar los cambios y exigencias constantes que se van produciendo.

\section{REFERENCIAS}

Amiama-Espaillat, Cristina y Cristina Mayor-Ruiz. 2017. "Lectura digital en la competencia lectora: La influencia en la generación z de la República Dominicana”. Comunicar 25 (52): 105-114. doi: 10.3916/C52-2017-10

Area-Moreira, Manuel. 2012. "La alfabetización en la sociedad digital", en Alfabetización digital y competencias informacionales, Manuel Area-Moreina, Alfonso Gutiérrez-Martín y Fernando Vidal-Fernández (coords.), 5-40. Barcelona: Fundación Telefónica-Ariel. http://www.observatorioabaco.es/biblioteca/docs/147_ FT_ALFABETIZACION_DIGITAL_2012.pdf

Area-Moreira, Manuel y Amador Guarro. 2012. "La alfabetización informacional y digital: fundamentos pedagógicos para la enseñanza y el aprendizaje competente”. Revista Española de Documentación Científica, número monográfico, 46-74. doi: 10.3989/redc.2012.mono.977

Bennet, Susan y Karl Maton. 2010. "Beyond the «digital natives» debate: towards a more nuanced understanding of students' technology experiences". Journal of Computer Assisted Learning 26 (5): 321-331. doi: 10.1111/j.1365-2729.2010.00360.x

Boyd, Danah. 2014. It's complicated: the social lives of networked teens. Estados Unidos: Yale University Press. http://www.danah.org/books/ItsComplicated.pdf 
Bustamante, Enrique. 2017. Informe sobre el estado de la cultura en España. Igualdady diversidad en la era digital (ICE-2017). Madrid: Fundación Alternativas. http:// www.fundacionalternativas.org/public/storage/publicaciones_archivos/6cd717bd9f96c0d102a67139fa3ea3ac.pdf

Cabra-Torres, Fabiola y Gloria-Patricia Marciales-Vivas. 2009. "Mitos, realidades y preguntas de investigación sobre los 'nativos digitales': una revisión”. Universitas Psychologica 8 (2): 323-338. http://www.scielo.org.co/pdf/rups/v8n2/v8n2a03.pdf

Cassany, Daniel. 2016. "Enseñar prácticas lectoras digitales”, en Educación social y alfabetización lectora, Santiago Yubero, José-Antonio Caride, Elisa Larrañaga y Héctor Pose (coords.), 77-98. Madrid: Síntesis.

Colás-Bravo, Pilar, Teresa González-Ramírez y Juan De-Pablos-Pons. 2013. "Juventud y redes sociales: Motivaciones y usos preferentes". Comunicar 20 (40): 15-23. doi: 10.3916/C40-2013-02-01

Cordón-García, José-Antonio. 2016. "La investigación sobre el entorno digital”. Métodos de Información 7 (13): 247-268. doi: 10.5557/IIMEI7-N13-247268

Dornaleteche, Jon, Alejandro Buitrago y Luisa Moreno. 2015. "Categorización, selección de ítems y aplicación del test de alfabetización digital on-line como indicador de la competencia mediática". Comunicar 22 (44): 177-185. doi: 10.3916/ C44-2015-19

Duart, Josep-María, Marc Gil, María Pujol y Jonatan Castaño. 2008. La universidad en la sociedad red. Usos de internet en la educación superior. Barcelona: Ariel. http://federacioneditores.org/img/documentos/HabitosLecturaCompraLibros2017.pdf

Federación de Gremios de Editores de España. 2018. Barómetro de bábitos de lectura y compra de libros en España 2017. http://federacioneditores.org/img/documentos/HabitosLecturaCompraLibros2017.pdf

García-Rueda, José-Jesús. 2008. "E-Learning en la empresa: ¿hay sitio para el aprendizaje informal?”. Quaderns Digitals 51. http://www.quadernsdigitals.net/index. php? accionMenu=hemeroteca.DescargaArticuloIU.descarga\&tipo=PDF \&articulo_id=10431

Gutiérrez-Porlán, Isabel, Marimar Román-García y María-del-Mar Sánchez-Vera. 2018. "Estrategias para la comunicación y el trabajo colaborativo en red de los estudiantes universitarios”. Comunicar 26 (54): 91-100. doi: 10.3916/C54-2018-09

Instituto de la Juventud. 2013. Informe Juventud en España 2012. Madrid: Instituto de la Juventud. http://www.injuve.es/sites/default/files/IJE2012_0.pdf

Larrañaga, Elisa y Santiago Yubero. 2005. "El hábito lector como actitud. El origen de la categoría de falsos lectores”. Ocnos 1: 43-30. doi: 10.18239/ocnos_2005.01.04

López-Ruiz, José-Antonio. 2017. "Cultura y ocio juveniles: jóvenes espectadores y actores en la diversidad actual”, en Jóvenes españoles entre dos siglos 1984-2017, Juan-María González-Anleo y José-Antonio López-Ruiz (coords.), 167-233. Madrid: Fundación SM-Observatorio de la juventud en Iberoamérica. http://vevangelizacionmadrid.com/images/Documentos/Temporales/Informe\%20Jo\% C2\%B4venes\%2084-17.pdf

Mckenna, Michael, Kristin Conradi, Camille Lawrence, Bong Gee y Patrick Meyer. 2012. "Reading attitudes of middle school students: results of a U.S. survey". Reading Research Quarterly 47 (3): 283-306. doi: 10.1002/RRQ.021

Millán, José-Antonio. 2000. La lectura y la sociedad del conocimiento. http://dpto. educacion.navarra.es/publicaciones/pdf/lecturajamillan.pdf 
Ministerio del Interior. 2014. Encuesta sobre bábitos de uso y seguridad de internet de menores y jóvenes en España. http://www.interior.gob.es/documents/10180/2563633/ Encuesta+sobre+h\%C3\%A1bitos+de+uso+y+seguridad+de+internet+de+menores+y+j\%C3\%B3venes+en+Espa \%C3\%B1a/b88a590a-514d-49a2-9162-f58b7e$2 \mathrm{cb} 354$

Pérez-Lorido, Martín. 2008. “Campus virtuales en universidades presenciales: ¿sueñan los estudiantes con profesores eléctricos?”. Revista Latinoamericana de Tecnología Educativa 7 (1): 85-95. https://relatec.unex.es/article/view/407/329

Prensky, Marc. 2001. "Digital natives, digital immigrants". On the horizon 9 (5): 1 16. doi: $10.1108 / 10748120110424816$

Rowlands, Ian, David Nicolas, Peter Williams, Paul Huntington, Maggie Fieldhouse, Barnie Gunter, Richard Whitney, Hamid R. Jamali, Tom Dobrowolski y Carol Tenopir. 2008. "The google generation: information behaviour of the researcher of the future". Aslib Proceeding 60 (4): 290-310. doi: 10.1108/00012530810887953

Subrahmanyam, Kaveri, David Smahel y Patricia Greenfield. 2006. "Connecting developmental constructions to the internet: Identity presentation and sexual exploration in online teen chat rooms". Developmental Psychology 42 (3): 395-406. doi: 10.1037/0012-1649.42.3.395

White, David y Alison Le-Cornu. 2011. "Visitors and residents: A new typology for online Engagement”. First Monday 16 (9). https://journals.uic.edu/ojs/index. $\mathrm{php} / \mathrm{fm} / \mathrm{article} / \mathrm{view} / 3171$

Yubero, Santiago y Elisa Larrañaga. 2015. "Lectura y universidad: estudio de los hábitos lectores de los estudiantes universitarios de España y Portugal”. El Profesional de la Información 24 (6): 713-719. doi: 10.3145/epi.2015.nov.03

Para citar este texto:

Elche Larrañaga, María y Santiago Yubero. 2019. "La influencia del hábito lector en el empleo de internet: un estudio con jóvenes universitarios”. Investigación Bibliotecológica: archivonomía, bibliotecología e información 33 (79): 51-66.

http://dx.doi.org/10.22201/iibi.24488321xe.2019.79.57985 